\title{
THE GEOCHRONOLOGY AND STRATIGRAPHIC EVOLUTION OF NEOGENE SEDIMENTARY ROCKS IN JACKSON HOLE, WYOMING
}

\author{
Douglas W. Burbank \\ Department of Geological Sciences \\ University of Southern California \\ Los Angeles
}

\section{Objectives}

The Miocene sediments of the Jackson Hole area constitute a unique sequence of terrestrial sediments. While much of the surrounding terrain was undergoing denudation during the Miocene, over $4000 \mathrm{~m}$ of volcaniclastic, lacustrine, and fluvial sediments accumulated in the vicinity of Jackson Hole. Recently completed paleontological and palynological studies have served to delineate complex biostratigraphic and climatic histories. The present research project has several goals. Chronologies are being developed for the Miocene sediments through the use of magnetic-polarity stratigraphies and fission-track dating. Sedimentation histories are being studied by combining lithologic data with chronologic information.

The results from the first year and a half of this project have raised some provocative questions. For example, sedimentation in the Teewinot Lake was very rapid, and yet the clastic influx into the lake appears minimal. Why was the detrital component so small? Where were the Tetons $10 \mathrm{~m} . \mathrm{y}$. ago, when the Teewinot Lake was flourishing? If there was no high relief to the west of the lake, when did the Tetons begin rising to their present configuration? In order to address these questions, an additional phase of study is being undertaken. Through the use of fission-track dating of mineral separates (zircon and apatite) obtained from the crystalline rocks of the Teton Range and Gros Ventre Range, uplift histories will be examined. When considered all together, the chronologies, stratigraphic histories, climatic record, and uplift histories will permit a detailed reconstruction to be made of the Miocene geologic history of Jackson Hole.

\section{Methodology}

The development of a reliable magnetostratioraphy usually requires successive sampling traverses. Initially, samples are spaced in such a way as to detect as much as possible of the overall structure of the magnetic record. Subsequently, the sampling is designed to provide more detail and increase the interval of dated sediments through sampling of additional sections. In later traverses, more attention is focused on the lichological characteristics and tectonic implications of the sediments being studied. Selected volcanic ashes have been sampled for fission-track dating in order to determine their time of eruption and the age of the adjacent sediments. 
The uplift studies are based on dating different mineral separates (zircon and apatite) from bulk samples collected at known elevations and structural positions within the ranges of interest. Because these minerals anneal at different temperatures, their ages reflect the geo-thermal history of the individual sample. When combined with data on geothermal gradients, these dates can be used to interpret the timing and magnitude of uplift. About a dozen samples are being collected for fission-track uplift studies from the Teton and Gros Ventre Ranges.

\section{Research Results}

In 1983, four weeks of field work were completed as part of the effort to develop a chronology for the Teewinot Formation. In the National Elk Refuge, about $900 \mathrm{~m}$ of Teewinot sediments were measured and described. Additional sections were measured along Kelly Road and at Haybarn Hill. In the main sequence, 65 paleomagnetic sampling sites were placed, and at each 3 specimens were collected. 2 dozen lithological samples were collected for sedimentological study, and bulk samples were collected at 3 sites for radiometric dating.

The results to date from the magnetic studies in the Elk Refuge and at the Kelly Road site are shown in Figures 1 and 2. In the Elk Refuge section, only about $1 / 3$ of the sites yielded reliable magnetic data (Class I sites). As a result, many gaps are present in the magnetic-polarity information. It appears that most of the unreliable magnetic data are due to the failure to sample undisturbed bedrock. Therefore, in 1984, sampling was designed to fill the gap in the previous year's record, and only outcrops that were clearly in place were sampled. One $\mathrm{K}$-Ar date of $10.30 .6 \mathrm{~m} . \mathrm{y}$. was determined for the Elk Refuge section. Two additional fission-track dates are presently being processed. The Kelly Road site yielded rather good magnetic data, and a tentative correlation with the global magnetic time scale is shown in Figure 2. If this interpretation is correct, it implies a much longer duration than was previously suggested for this 70 -m-thick portion of the Teewinot Formation.

The field work in 1984 was designed to clarify ambiguities in the magnetic record and to reconfirm the placement of this section in the context of the global reversal time scale. Sampling was also carried out for lithological analysis, ostracod collections, and additional fission-track dating. Thus far, over 8000 magnetic measurements have been made on 230 samples collected in 1983. An additional 100 samples were collected from the Elk Refuge and Kelly Road sections in August, 1984. These are presently being analyzed.

The base of the Elk Refuge section is poorly exposed and does not include the depositional base of the Teewinot Formation. To try to delineate the timing and nature of sedimentation in the early stages of deposition of the Teewinot, a new section was measured and sampled in 1984 near the Teton Science School. These samples are also being analyzed at the present time. 


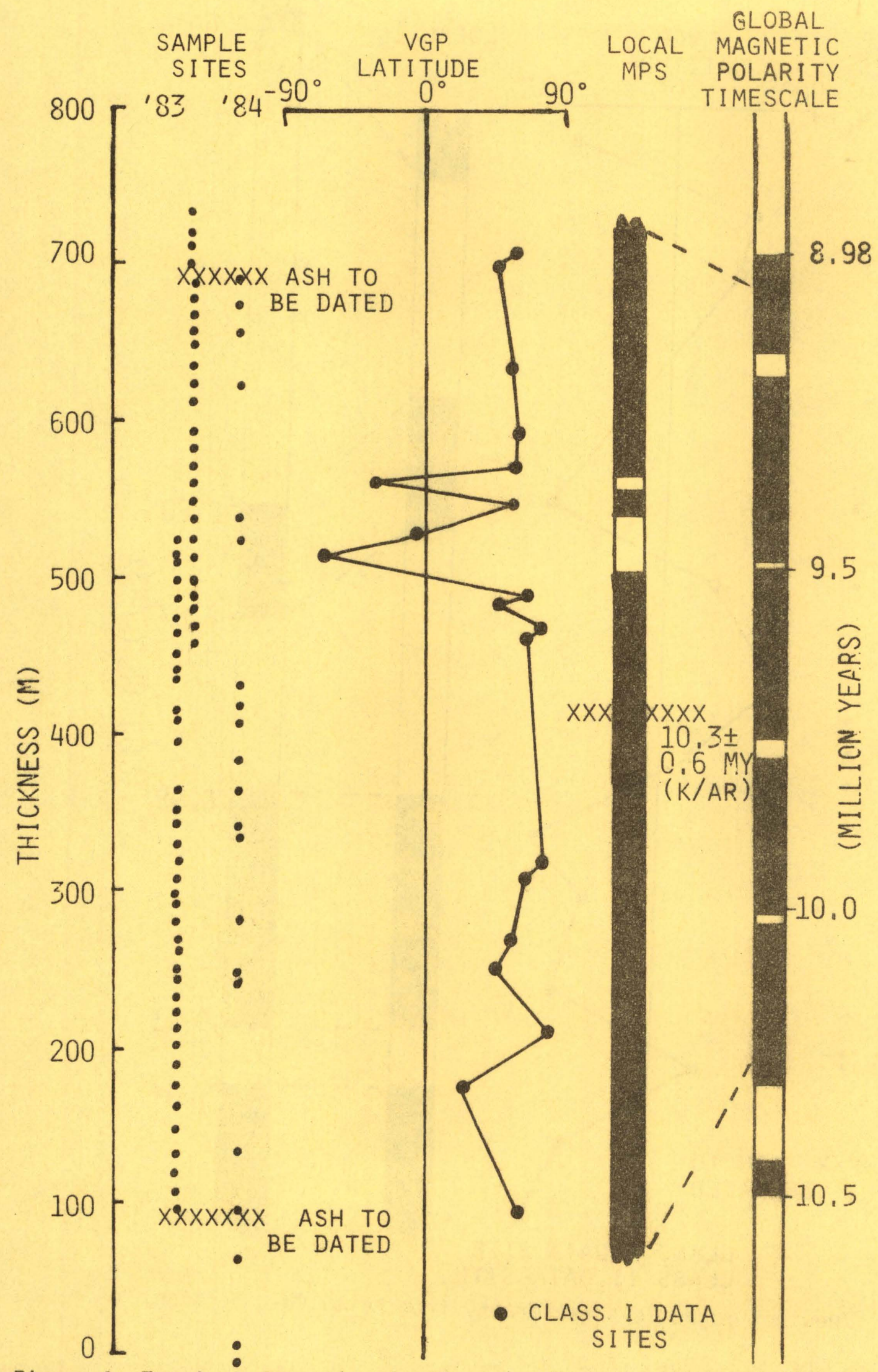

Figure 1. Teewinot magnetic stratigraphy from the National Elk Refuge. 
TIMESCALE

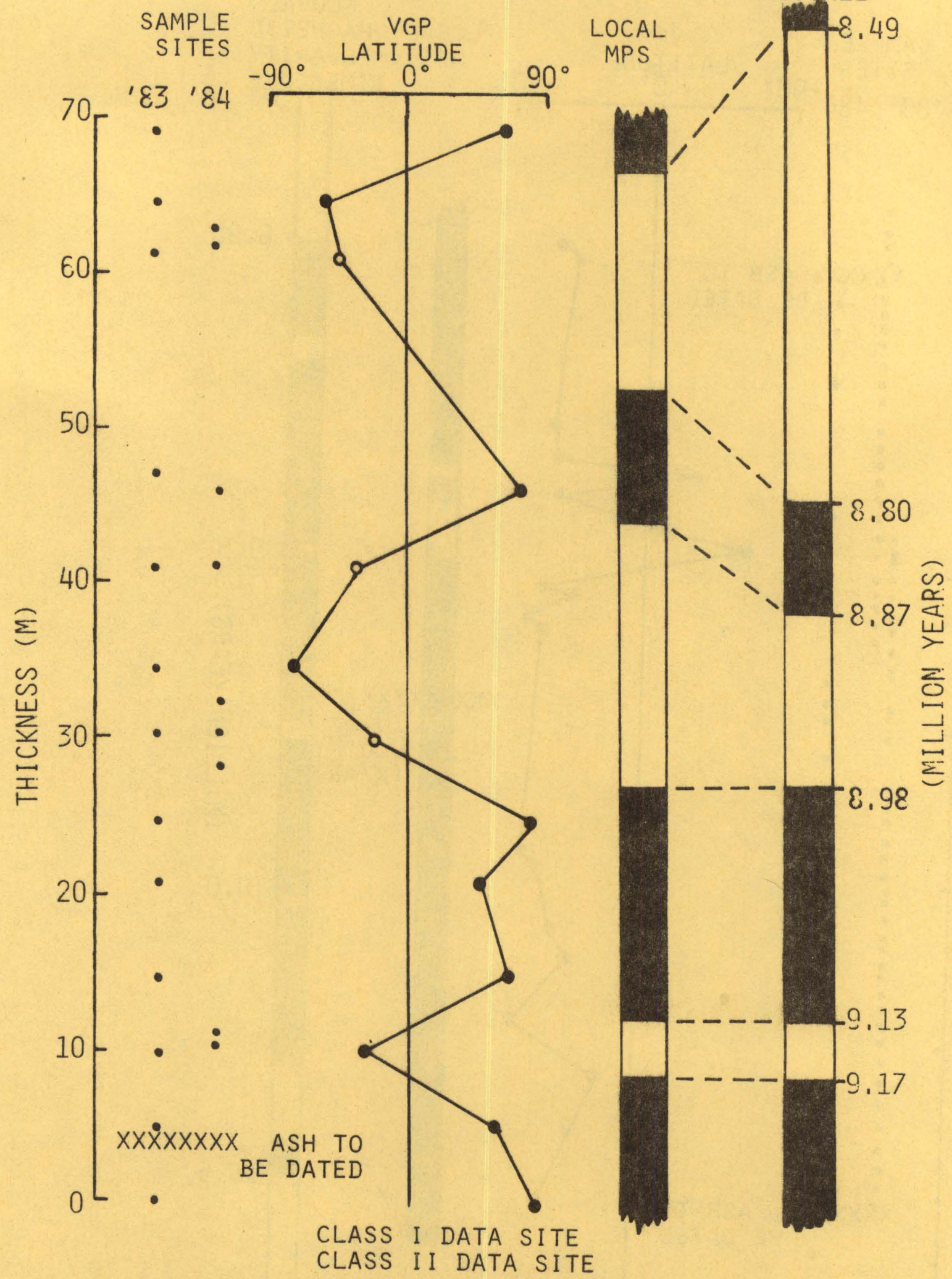

Figure 2. Teewinot magnetic stratigraphy from Kelly Road section. 


\section{Conclusions}

The results of the magnetic studies to date have been encouraging. The stable magnetic properties of many of the samples permit their characteristic remanence directions to be determined quite confidently. More work is needed to verify and enlarge the present results. The present interpretation of these sequences suggests that there have been major changes in the rates of sediment accumulation during the late Miocene. These changes may have resulted from the initial pulses of uplift of the Teton Range. This possibility is now being investigated by developing preliminary uplift histories for several ranges based on fission-track dating.

Despite the need for further chronologic work on the Teewinot, the present results indicate that the bulk of Teewinot sediments accumulated between about 10 and 8.5 m.y. ago. During this time, major changes occurred in the style of sedimentation, the composition of the lake sediments, and the geometry of the depositional basin. A full description of the Miocene paleoenvironments encompassed by the Teewinot Formation must await forthcoming research results. 